\title{
Role of Group-specific Component (Vitamin D Binding Protein) in Clearance of Actin from the Circulation in the Rabbit
}

\author{
Pascal J. Goldschmidt-Clermont," Hugo Van Baelen," Roger Bouillon," Thomas E. Shook," Merfyn H. Williams," \\ Andre E. Nel," and Robert M. Galbraith*' \\ *Departments of Microbiology and Immunology, Urology, and 'Medicine, Medical University of South Carolina, Charleston, South \\ Carolina, 29425; ' Laboratorium voor Experimentale Geneeskunde, Katholieke Universiteit te Leuven, B-3000, Leuven, Belgium, \\ and "Department of Internal Medicine, Stellenbosch Medical School, Cape Town, Republic of South Africa
}

\begin{abstract}
The possible role of group specific component (Gc) (vitamin D-binding protein) in the clearance of cellular actin entering the circulation was examined with ${ }^{125}$ I-labeled Gc and actin injected into a rabbit model. Although filamentous F-actin is depolymerized primarily by plasma gelsolin, $\geq 90 \%{ }^{125}$ I-actin injected in either monomeric G- or F-form became complexed eventually with Gc (1:1 molar ratio). Clearance of Gc complexes was much faster ( $>90 \%$ within $5 \mathrm{~h}$ ) than that of native Gc $\left(t_{1 / 2}=17.2 \mathrm{~h}\right)$. Nephrectomy did not significantly alter the clearance of either Gc or actin. Since Gc complexes are dramatically increased in situations of tissue necrosis such as in fulminant hepatic failure, the current results suggest a crucial role for $\mathrm{Gc}$ in sequestration and clearance of released cellular actin.
\end{abstract}

\section{Introduction}

Group specific component $(\mathrm{Gc})^{1}$ is an alpha ${ }_{2}$ glycoprotein in plasma (1-3) that was shown in 1975 to be the major carrier for vitamin $D_{3}$ metabolites $\left(D_{3}\right)$ in a variety of mammalian species (4). Gc has primarily been considered to be a component of the extracellular space. However, a protein physicochemically homologous to $\mathrm{Gc}\left(M_{\mathrm{r}} 56,000, \mathrm{pl}\right.$ 4.8-5.0) has been described on the surface membrane of B lymphocytes where it codistributes with membrane immunoglobulin (5), on $\mathrm{T}$ cells in relation to the Fc gamma receptor (6), and also in the cytoplasm of many nucleated cells $(7,8)$. Structural studies of plasma and cellular Gc have been limited to date, but recent sequencing of protein and full-length cDNA prepared from rat and human liver RNA has shown considerable sequence homology between $\mathrm{Gc}$, and both albumin and alpha $\mathrm{a}_{1}$-fetoprotein (9-12). Moreover, these proteins have been shown to be coded by genes present on chromosome 4 and may therefore constitute a protein family derived from a common ancestral gene $(10,11)$.

Address reprint requests to Dr. R. M. Galbraith, Department of Microbiology and Immunology, Medical University of South Carolina, Charleston, SC 29425-2230.

Received for publication 11 August 1986 and in revised form 23 November 1987.

1. Abbreviations used in this paper: $\mathrm{D}_{3}$, vitamin $\mathrm{D}_{3} ; 25-(\mathrm{OH}) \mathrm{D}_{3}$, 25-hydroxychole-calciferol; Gc, group specific component; IEF, analytical isoelectric focusing.

J. Clin. Invest.

(c) The American Society for Clinical Investigation, Inc. 0021-9738/88/05/1519/09 \$2.00

Volume 81, May 1988, 1519-1527
The widespread occurrence of $\mathrm{Gc}$ in various animal species (13) suggests a crucial role for this protein, and no instance of plasma Gc deficiency has been found in more than 75,000 human samples tested (14). However, the precise function(s) of $\mathrm{Gc}$ have not yet been elucidated. The transport of vitamin D metabolites does not seem to be its only biological role, since $<5 \%$ of plasma $\mathrm{Gc}$ is complexed with $\mathrm{D}_{3}$ at any given time (15), and no consistent relationship between $\mathrm{Gc}$ levels and the concentration of bound sterols has been demonstrated in health or disease $(16,17)$. Moreover, although relevant studies have been limited, the reported plasma half-life of Gc appears considerably shorter both in humans $\left[t_{1 / 2}=\sim 2.5 \mathrm{~d}(18)\right]$ and in rabbits $\left[t_{1 / 2}=1.7 \mathrm{~d}(19)\right]$ than that of the major associated $\mathrm{D}_{3}$ metabolite, 25-hydroxy-cholecalciferol (25-(OH) $\left.\mathrm{D}_{3}\right)$, for which $t_{1 / 2}=11.3 \mathrm{~d}$ in the rabbit (19).

Recently, a high affinity 1:1 molar ratio interaction has been demonstrated between $\mathrm{Gc}$ and the monomeric or globular G-form of actin (20-22). Formation of this complex in vitro inhibits polymerization of actin to the filamentous or F-form, and also effects depolymerization of F-actin at stoichiometric concentrations $(20,21)$. Gc may therefore be considered as a true G-actin-sequestering protein, and this has led to the suggestion that it acts as a scavenger of actin (20). In contrast, plasma gelsolin (or brevin), the other major actin-depolymerizing protein in the extracellular space, primarily severs actin filaments at substoichiometric concentrations (23-26).

Although direct evidence of actin in the circulation is lacking, it appears likely that this protein would be released as a result of cell death, either as a physiological event related to normal tissue turnover, also termed apoptosis $(27,28)$, or in an uncontrolled fashion due to environmental perturbation. Apoptosis seems to be a highly organized and relatively slow mechanism by which cells separate into fragments bounded by membrane, which are then phagocytosed by adjacent cells. The process of necrosis is more sudden and culminates in rupture of the plasma membrane (27). This results in dispersion of cellular components into the extracellular space, including presumably large amounts of actin, which represents $10-20 \%$ of total protein contained in most cells (29). We have reported evidence indicating that a proportion of plasma or serum $\mathrm{Gc}$ is complexed with protein, which may include actin or fragments thereof, both in health and disease (30-33). Although the percentage of complexed Gc is small in normal controls $(32,33)$, this may increase to $>90 \%$ in conditions of enhanced tissue turnover or damage such as fulminant hepatic failure (31-33). Recently, Lind et al. demonstrated rapid clearance of injected F-actin (50\% in $~ 30 \mathrm{~min}$ ) in rabbits, and concluded that while plasma gelsolin is clearly crucial for depolymerization of actin, it may play a role secondary to that 
of $\mathrm{Gc}$ in subsequent clearance of this protein from the circulation (34).

In this study, we further investigated the plasma clearance of actin by $\mathrm{Gc}$. Injection of ${ }^{125} \mathrm{I}$-labeled actin into rabbits led to binding of $\geq 90 \%$ to $\mathrm{Gc}$ within $5 \mathrm{~min}$, regardless of whether actin was injected in G- or F-form. Moreover, clearance of such complexed Gc was substantially more rapid than that of native Gc. Parallel in vitro experiments in humans involving addition of ${ }^{125} \mathrm{I}$-F-actin to whole serum or plasma also showed binding of $>80 \%$ of radioactivity to Gc. These findings suggest that a major function of Gc may be to assist in clearance of actin from the extracellular space.

\section{Methods}

Protein purification and labeling. Rabbit skeletal muscle actin, rabbit serum $\mathrm{Gc}$ and human serum $\mathrm{Gc}$ were purified and radioiodinated with ${ }^{125}$ I using methods previously described $(22,35,36)$ under conditions ensuring incorporation of $\leq 1$ molecule ${ }^{125} \mathrm{I}$ per molecule protein on tyrosine amino acid 53 (37). Specific activities obtained for human and rabbit Gc were $0.8-1.9 \mu \mathrm{Ci} \mu \mathrm{g}^{-1}$, and for rabbit G-actin $0.5-1.0 \mu \mathrm{Ci}$ $\mu \mathrm{g}^{-1}$. Rabbit albumin was purchased from Sigma Chemical Co., St. Louis, MO, and radioiodinated using the lactoperoxidase method, which resulted in labeled protein of specific activity 4-5 $\mu \mathrm{Ci} \mu \mathrm{g}^{-1}$. Unbound ${ }^{125}$ I was removed by desalting on prepacked PD-10 columns containing Sephadex G-25 (Pharmacia Fine Chemicals, Piscataway, $\mathrm{NJ}$ ), and such radiolabeled preparations were consistently $>99 \%$ precipitable with $12.5 \%$ TCA. To verify retention of native properties, all labeled preparations were examined before use by SDS-PAGE, PAGE and analytical isoelectric focusing (IEF - see below), in parallel with homologous cold protein (Fig. 1). Radioiodinated proteins were also analyzed for retention of ability to bind known ligands-unlabeled 25-(OH) $D_{3}, G$-actin and DNase (22) in the case of ${ }^{125} \mathrm{I}-\mathrm{Gc}$, and unlabeled $\mathrm{Gc}$ in the case of ${ }^{125} \mathrm{I}-\mathrm{G}$-actin. Since detailed characterization of rabbit $\mathrm{Gc}$ after complex formation with $25-(\mathrm{OH}) \mathrm{D}_{3}$ or G-actin had not been previously performed, purified rabbit $\mathrm{Gc}$ was analyzed in parallel with human $\mathrm{Gc}$ for which such information has already been obtained

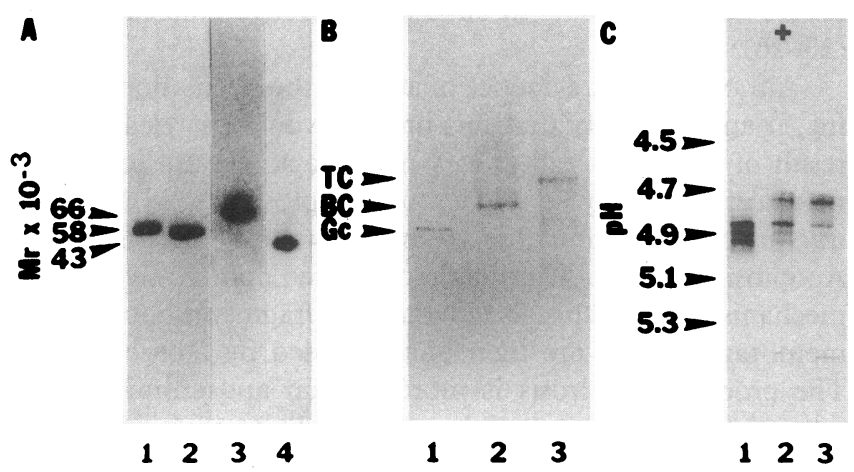

Figure 1. Characterization of radiolabeled proteins $(A)$ SDS-PAGE with autoradiography $-10 \mathrm{ng}$ each of 1 . rabbit ${ }^{125} \mathrm{I}-\mathrm{Gc}$; 2 . human ${ }^{125} \mathrm{I}-\mathrm{Gc}$; 3. rabbit ${ }^{125} \mathrm{I}$-albumin; and 4. ${ }^{125} \mathrm{I}-\mathrm{G}$-actin: (B) PAGE in the absence of SDS, stained with Coomassie Brilliant Blue; $5 \mu \mathrm{g}$ of rabbit $\mathrm{Gc}$ was run 1 . alone; 2 . as a binary complex $(\mathrm{BC})$ with $\mathrm{G}$-actin (molar ratio 1:1); and 3. as a ternary complex (TC) with G-actin and bovine DNase (molar ratio 1:1:1). The electrophoretic mobilities were similar to those obtained with human Gc (22): C. IEF stained with silver (anode at the top); $10 \mathrm{ng}$ rabbit Gc was run 1. alone; 2. after addition of $25-(\mathrm{OH}) \mathrm{D}_{3}$ (molar ratio $2: 1 \mathrm{Gc}: 25-(\mathrm{OH}) \mathrm{D}_{3}$ ); and after addition of G-actin (molar ratio 2:1 Gc:G-actin). In the case of both $B$ and $C$, autoradiography showed that essentially all radiolabeled $\mathrm{Gc}$ was functional in such binding assays.
$(22,30)$. The ability of ${ }^{125} \mathrm{I}-\mathrm{G}$-actin to undergo polymerization (38) was also checked by pelleting assays (39).

Animal experiments. New Zealand White rabbits (2.5-4.5 kg) were fed regular chow and water ad libitum, and kept in metabolic cages for the duration of the experiments. An intravenous catheter (22 gauge; Critikon, Tampa, FL) was placed in the marginal vein of the ear and used for all injections. Samples for administration to the animal were sterilized by filtration through Acrodiscs $(0.2 \mu \mathrm{m}$ pore size; Gelman Sciences Inc., Ann Arbor, MI). Before injection of radioiodinated proteins, $5 \mathrm{mg}$ i.v. of cold $\mathrm{KI}$ was slowly administered.

Rabbit ${ }^{125} \mathrm{I}-\mathrm{Gc}$ was used throughout for injection, $40-200 \mu \mathrm{Ci}$ being administered either alone, or after incubation with saturating amounts of unlabeled G-actin (Gc:G-actin ratio $=1: 2-1: 10$ ) for 15 min at $22^{\circ} \mathrm{C}$. For experiments involving ${ }^{125} \mathrm{I}-\mathrm{F}$-actin, $40-60 \mu \mathrm{Ci}$ in G-buffer (5 mM Tris, pH 7.5, 0.1 mM ATP, 0.1 $\mathrm{mM} \mathrm{CaCl}_{2}, 0.5 \mathrm{mM}$ DTT) was centrifuged together with unlabeled actin at concentrations above critical $(100,000 \mathrm{~g}$ for $60 \mathrm{~min})$ to remove aggregated protein, and was then polymerized by addition of $100 \mathrm{mM} \mathrm{KCl}$ and $1 \mathrm{mM} \mathrm{MgCl}$ (F-buffer). After $30 \mathrm{~min}$ incubation, the samples were centrifuged for $60 \mathrm{~min}$ at $100,000 \mathrm{~g}$ at $22^{\circ} \mathrm{C}$. Pelleting assays (39) showed that $>90 \%$ ${ }^{125} \mathrm{I}$-actin was in the F-form. ${ }^{125} \mathrm{I}-\mathrm{G}$-actin was prepared in one of two ways. First, the supernatant obtained by centrifugation at $100,000 \mathrm{~g}$ was used without further manipulation. Second, to investigate the possibility that such ${ }^{125} \mathrm{I}-\mathrm{G}$-actin preparations contained altered actin, actin was subjected after radiolabeling to a cycle of polymerization/depolymerization by addition of F-buffer and centrifugation as above, followed by resuspension of the pellet obtained at subcritical concentrations (38). As judged by pelleting assays (38), these preparations both contained $>90 \%{ }^{125} \mathrm{I}$-actin in the $\mathrm{G}$ form, and gave equivalent results. Finally, for experiments involving ${ }^{125} \mathrm{I}$-albumin, $200-400 \mu \mathrm{Ci}$ was injected.

Blood samples $(2-3 \mathrm{ml})$ were collected, from vessels opposite to those used for injection, into evacuated glass tubes containing sodium heparin (Becton-Dickinson Co., Rutherford, NJ). Plasma was separated by centrifugation at $1000 \mathrm{~g}$ for $3 \mathrm{~min}$ at $22^{\circ} \mathrm{C}$. An aliquot $(100-1,000 \mu \mathrm{l})$ was counted in a gamma counter. Since complexes between $\mathrm{Gc}$ and actin have been found to be stable for at least 2 mo at $-70^{\circ} \mathrm{C}$, even after radiolabeling (unpublished observations), samples were occasionally stored frozen for up to a week when immediate assay was not feasible. Urine was collected from the bottom of the metabolic cage, and an aliquot $(100-1,000 \mu \mathrm{l})$ was centrifuged in a glass tube $\left(1,000 \mathrm{~g}\right.$ for $3 \mathrm{~min}$ at $\left.22^{\circ} \mathrm{C}\right)$ and counted in a gamma counter. Another aliquot was submitted to precipitation with $12.5 \% \mathrm{TCA}$, and the resulting pellet and supernatant were counted separately. For some experiments, male rabbits were sedated with $25 \mathrm{mg} / \mathrm{kg}$ body wt pentobarbital i.v., in order to allow the placement of catheter into the urinary tract to empty the bladder before the start of the experiment and to collect samples during the first $6 \mathrm{~h}$ after injection. Animals were killed at various times after injection of the labeled proteins by intracardiac injection of a lethal dose $(250 \mathrm{mg})$ of pentobarbital.

Four rabbits were bilaterally nephrectomized under general anesthesia ( $20 \mathrm{mg} \mathrm{kg}^{-1}$ ketamine from Bristol Laboratories, Syracuse, NY) and sterile surgical conditions. Labeled proteins were injected $1 \mathrm{~h}$ after completion of surgery, and plasma samples were obtained as described for normal animals. Survival of nephrectomized rabbits for up to $54 \mathrm{~h}$ was ensured by peritoneal dialysis initiated at $24 \mathrm{~h}$ after surgery. The catheter was placed intraperitoneally during nephrectomy, and two 100 -ml exchanges of sterile dialysis fluid $\left(5 \mathrm{mM} \mathrm{MgCl}_{2}, 10 \mathrm{mM} \mathrm{Ca}\right.$ lactate, $120 \mathrm{mM} \mathrm{NaCl}, 300 \mathrm{mM}$ glucose, $\mathrm{pH} 7.4$ ) were administered twice daily for 30-min periods.

Antiserum to rabbit Gc. Polyclonal antisera were raised in sheep by immunization with purified rabbit $\mathrm{Gc}$. Monospecificity of the antisera obtained was verified by immunoelectrophoresis (32). Moreover, such antisera were found to immunoprecipitate rabbit $\mathrm{Gc}$ in both native and complexed forms, as has been shown previously by rocket immunoelectrophoresis in the case of antisera to human Gc $(32,33,35)$.

Immunoprecipitation assays. 50 or $100 \mu \mathrm{l}$ of samples were mixed with 50 or $100 \mu \mathrm{l}$ of antiserum monospecific for $\mathrm{Gc}$ and incubated for 
45 min. Washed Staphylococcus aureus (Calbiochem-Behring Diagnostics, La Jolla, CA), 200 or $400 \mu$ l, respectively, were added to the sample. After $30 \mathrm{~min}$ incubation the pellet was washed three times in PBS, and then resuspended in nonreducing SDS-PAGE sample buffer for $30 \mathrm{~min}$. After centrifugation at $12,000 \mathrm{~g}$ for $5 \mathrm{~min}$, the supernatant was removed, boiled for $5 \mathrm{~min}$, counted and analyzed by SDS-PAGE.

Chromatographic methods. Gel filtration was performed on Sephadex G-100 superfine in a column $7 \times 880 \mathrm{~mm}$-bed volume 135 $\mathrm{ml}$-with $30 \mathrm{mM}$ phosphate buffer, $\mathrm{pH}$ 7.0. After application of samples $(0.1-0.8 \mathrm{ml})$, elution was performed at a rate of $6.9 \mathrm{ml} \mathrm{h}^{-1}$ at $22^{\circ} \mathrm{C}$ and $2.3-\mathrm{ml}$ fractions were collected. The optical density profile (280 $\mathrm{nm}$ ) was recorded.

Electrophoretic methods. Polyacrylamide gel electrophoresis (PAGE) was performed with and without SDS, using continuous $(5-20 \%)$ gradient gels $(22,39)$. Where appropriate, the gels were dried and submitted to autoradiography. Fused rocket immunoelectrophoresis and crossed immunoelectrophoresis (CIEP) were carried out as described (35) using sheep antiserum to rabbit $\mathrm{Gc}$ and rabbit antiserum to human Gc, respectively ( $2 \%$ in agarose vol/vol). Flat bed thin layer isoelectric focusing was performed in non-denaturing conditions as reported (22).

\section{Statistical analysis}

Differences in the results obtained were analyzed by Wilcoxon's rank sum sign test.

\section{Results}

Characterization of labeled proteins. Purified rabbit and human ${ }^{125} \mathrm{I}-\mathrm{Gc}$ preparations were $>95 \%$ homogeneous as assessed by SDS-PAGE and autoradiography. Uncomplexed rabbit Gc was slightly larger $\left(M_{\mathrm{r}} 58,000\right)$ than its human counterpart $\left(M_{\mathrm{r}} 56,000\right.$, Fig. 1), but the relative mobilities of both radioiodinated $\mathrm{Gc}$ preparations were identical to those observed with the homologous cold proteins (Fig. 1). Moreover, IEF and PAGE in non-denaturing conditions demonstrated further evidence of retention of native properties in that rabbit ${ }^{125} \mathrm{I}-\mathrm{Gc}$ formed binary complexes with G-actin, and ternary complexes with G-actin:DNase (Fig. 1) in a fashion similar to that found previously with human Gc (22). Rabbit ${ }^{125} \mathrm{I}-\mathrm{Gc}$ also formed complexes of 1:1 molar ratio with 25-(OH) $\mathrm{D}_{3}$ with a charge shift analogous to the anodal migration of human Gc:25-(OH) $\mathrm{D}_{3}$ complexes (35, Fig. 1). Similarly, ${ }^{125} \mathrm{I}-$ F-actin ( $>90 \%$ pelletable counts), ${ }^{125} \mathrm{I}-\mathrm{G}$-actin $(<10 \%$ pelletable counts), and ${ }^{125} \mathrm{I}$-albumin were $>95 \%$ homogeneous and migrated on SDS-PAGE to positions indistinguishable from those of the native proteins (Fig. 1); ${ }^{125} \mathrm{I}-\mathrm{G}$-actin preparations also retained the potential for polymerization (39).

Initial plasma disappearance studies. A rapid decrease in total plasma counts was observed with all radiolabeled proteins immediately after injection, and the relationship with time was multiexponential. Subsequently, the rate of loss of total radioactivity stabilized and became log-linear with time. Based upon total counts, the mean half life $\left(t_{1 / 2}\right)$ calculated from this portion of the ${ }^{125} \mathrm{I}-\mathrm{Gc}$ curve was $28.8 \mathrm{~h}$, a result not substantially different from the figure of $1.7 \mathrm{~d}$ reported earlier (19); similar calculations for ${ }^{125} \mathrm{I}$-actin and ${ }^{125} \mathrm{I}$-albumin gave figures of $19.5 \mathrm{~h}$ and $5.8 \mathrm{~d}$, respectively. In parallel with the plasma decay profiles, examination of urine samples showed a more rapid appearance of counts in the case of ${ }^{125} \mathrm{I}-\mathrm{Gc},{ }^{125} \mathrm{I}$ Gc:G-actin, and ${ }^{125} \mathrm{I}$-actin, than for ${ }^{125} \mathrm{I}$-albumin, and examination of urine counts showed that $<1 \%$ appeared to be protein-bound as judged by precipitability with $12.5 \%$ TCA.
Examination of plasma counts after gel filtration. Recent reports have demonstrated variable removal of covalently bound ${ }^{125} \mathrm{I}$ from injected proteins, raising the possibility of inaccuracies in $t_{1 / 2}$ measurements for the relevant proteins (40, 41). In view of this, experiments were performed to evaluate the proportions of ${ }^{125} \mathrm{I}$ counts circulating in free form, and protein-bound, as judged by gel filtration of samples obtained sequentially after injection. In the case of ${ }^{125} \mathrm{I}-\mathrm{Gc}$ and ${ }^{125} \mathrm{I}-$ Gc:G-actin, such analyses showed a clear initial reduction in the percentage of total ${ }^{125} \mathrm{I}$ counts found in the protein-containing fractions, from $\geq 95 \%$ at $5 \mathrm{~min}$ after injection to 65 and $63 \%$, respectively, at $7 \mathrm{~h}$ (Table I), although later observations showed stabilization or even a slight increase both for ${ }^{125} \mathrm{I}-\mathrm{Gc}$ and ${ }^{125} \mathrm{I}-\mathrm{Gc}: \mathrm{G}$-actin (Table I). Parallel experiments with ${ }^{125} \mathrm{I}$-actin showed an even faster decline, to $\leq 22 \%$ at $7 \mathrm{~h}$. In contrast, very little reduction in the percentage of counts bound to protein was apparent in the case of ${ }^{125} \mathrm{I}$-albumin, with $>90 \%$ of plasma radioactivity remaining protein-bound throughout the entire time period tested.

Examination of plasma counts after immunoprecipitation with anti-Gc. To examine the possibility that some proteinbound plasma counts might be unrelated to $\mathrm{Gc}$, as a result of secondary iodination or reutilization $(40,41)$, parallel studies involving specific immunoprecipitation were performed. Initial experiments verified the monospecificity of anti-Gc as assessed by immunoelectrophoresis. Moreover, when tracer ${ }^{125} \mathrm{I}$ Gc was added to serum samples in vitro, $>95 \%$ of the counts present were immunoprecipitated with anti-Gc, as against $<3 \%$ when nonimmune sheep serum was substituted for antiGc. Plasma samples from experiments involving ${ }^{125} \mathrm{I}-\mathrm{Gc}$ or ${ }^{125} \mathrm{I}-\mathrm{Gc}$ :G-actin were therefore examined after immunoprecipitation with anti-Gc. This showed a rapid time-dependent reduction in the percentage of counts immunoprecipitated with $\mathrm{Gc}$ in successive samples after injection. Moreover, the percentages of counts specifically brought down in relation to Gc were slightly but consistently lower than the percentages of counts protein-bound as judged by Sephadex G-100 filtration (Table I). For example, at $3 \mathrm{~h}$ after intravenous administration of ${ }^{125} \mathrm{I}-\mathrm{Gc}, 64 \%$ of counts were protein-bound as judged by gel filtration, whereas $42 \%$ were immunoprecipitable with anti-

Table I. Decrease in Percentage of Counts Bound to Protein or Specifically to Gc as a Function of Time

\begin{tabular}{|c|c|c|c|c|c|c|}
\hline \multirow[b]{2}{*}{ Time } & \multicolumn{2}{|c|}{${ }^{125} \mathrm{I}-\mathrm{Gc}$} & \multicolumn{2}{|c|}{${ }^{125} \mathrm{I}-\mathrm{Gc}: \mathrm{G}$-actin } & \multicolumn{2}{|c|}{${ }^{125}$ I-G-actin } \\
\hline & G-100 & anti-Gc & G-100 & anti-Gc & G-100 & anti-Gc \\
\hline $5 \mathrm{~min}$ & 97 & 89 & 95 & $(64)^{*}$ & 70 & 50 \\
\hline $60 \mathrm{~min}$ & 78 & 49 & 75 & 44 & - & - \\
\hline $3 \mathrm{~h}$ & 64 & 42 & 55 & 31 & 43 & 32 \\
\hline $7 \mathrm{~h}$ & 65 & 38 & 63 & 48 & 22 & 13 \\
\hline $14 \mathrm{~h}$ & 80 & 50 & 79 & 33 & - & - \\
\hline $24 \mathrm{~h}$ & - & 53 & - & 28 & 3 & 1.3 \\
\hline $33 \mathrm{~h}$ & - & 46 & - & 27 & - & - \\
\hline $54 \mathrm{~h}$ & - & 60 & - & 22 & - & - \\
\hline
\end{tabular}

After injection of rabbit ${ }^{125} \mathrm{I}-\mathrm{Gc},{ }^{125} \mathrm{I}-\mathrm{Gc}: \mathrm{G}$-actin or ${ }^{125} \mathrm{I}-\mathrm{G}$-actin, plasma samples were submitted to Sephadex G-100 chromatography or immunoprecipitation with anti-Gc as described in the text, and counted. The table shows the percentages of total counts in each sample bound to protein $(\mathrm{G} 100)$ or to $\mathrm{Gc}$ (anti-Gc); results are from a representative experiment.

* This sample was obtained at $9 \mathrm{~min}$. 
Gc. In samples containing ${ }^{125} \mathrm{I}-\mathrm{G}$-actin, treatment with anti-Gc brought down $\geq 50 \%$ of total counts at $5 \mathrm{~min}$, or $>70 \%$ of protein-bound counts as assessed by gel filtration, indicating complexing of injected actin with Gc (see below). Immunoprecipitation also showed a rapid decrease in immunoprecipitable counts in later samples (Table I).

Plasma clearance of radiolabeled proteins. These results (Table I) indicated the occurrence of substantial deiodination of ${ }^{125} \mathrm{I}-\mathrm{Gc}$ and ${ }^{125} \mathrm{I}-\mathrm{G}$-actin, and possible reutilization or secondary iodination of other unrelated proteins $(40,41)$. All subsequent measurements of plasma clearance were therefore calculated with counts obtained by immunoprecipitation of samples with anti-Gc ( ${ }^{125} \mathrm{I}-\mathrm{Gc}$ and $\left.{ }^{125} \mathrm{I}-\mathrm{Gc}: G-a c t i n\right)$, or G-100 gel filtration ( ${ }^{125} \mathrm{I}-\mathrm{G}$-actin). This indicated that plasma clearances of ${ }^{125} \mathrm{I}-\mathrm{Gc},{ }^{125} \mathrm{I}-\mathrm{Gc}$ :G-actin, and ${ }^{125} \mathrm{I}-\mathrm{G}$-actin were in fact substantially shorter than suggested on the basis of total plasma counts-17.2 $\pm 2.9 \mathrm{~h}(n=3), 15.0 \pm 1.5 \mathrm{~h}(n=3)$, and $5.3 \pm 0.5 \mathrm{~h}(n=3)$, respectively (Fig. 2$)$.

Complexing of injected ${ }^{125}$ I-actin with circulating Gc. Previous studies have shown that addition of actin to plasma in vitro leads to eventual interaction of the majority $(>95 \%)$ with Gc (35). In this study, $\geq 50 \%$ of total counts, or $\sim 70 \%$ of counts calculated to be protein-bound, were immunoprecipitable with anti-Gc 5 min after injection of ${ }^{125} \mathrm{I}-\mathrm{G}$-actin (Table I), indicating that injected ${ }^{125}$ I-actin also formed complexes with circulating $\mathrm{Gc}$ in vivo. Further analysis of protein-bound counts by gel filtration (Fig. 3) demonstrated background counts in the included volume fractions corresponding to the elution volume of ${ }^{125} \mathrm{I}-\mathrm{G}$-actin $\left(M_{\mathrm{r}} 43,000\right)$, and $\leq 5 \%$ of counts were found in a minor peak in the excluded volume with a calculated $M_{\mathrm{r}} \geq 150,000$. The remainder, $\geq 95 \%$, were localized in a major peak at 100,000 as calculated from molecular weight markers (Fig. 3), corresponding to the expected $M_{\mathrm{r}}$ of rabbit Gc complexed with G-actin, 101,000. The elution profiles obtained at 5 min after injection of either ${ }^{125} \mathrm{I}-\mathrm{Gc}: \mathrm{G}-$ actin or ${ }^{125} \mathrm{I}-\mathrm{F}$-actin were very similar to that obtained with ${ }^{125} \mathrm{I}-\mathrm{G}$-actin. In contrast, after administration of native ${ }^{125} \mathrm{I}-\mathrm{Gc}$ alone, $>95 \%$ of counts eluted at a calculated $M_{\mathrm{r}}$ of 55,000 (Fig. 3). Similar experiments in which ${ }^{125}$ I-G-actin samples drawn after 5 min were immunoprecipitated with anti-Gc

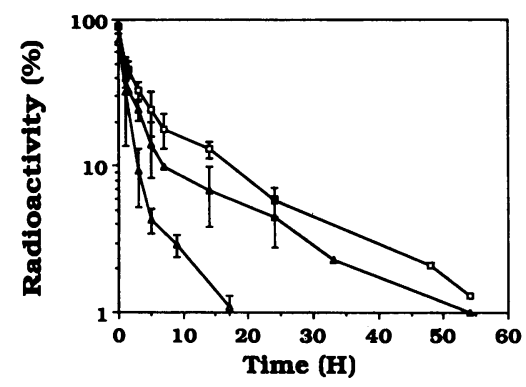

Figure 2. Plasma decay of protein-bound ${ }^{125}$ I counts after injection of rabbit ${ }^{125} \mathrm{I}-\mathrm{Gc}(60 \mu \mathrm{g}),{ }^{125} \mathrm{I}-\mathrm{Gc}: \mathrm{G}-a \mathrm{actin}(60 \mu \mathrm{g}: 160 \mu \mathrm{g})$, and ${ }^{125} \mathrm{I}-\mathrm{G}-$ actin $(80 \mu \mathrm{g})$. In the case of ${ }^{125} \mathrm{I}-\mathrm{Gc}(\square)$ and ${ }^{125} \mathrm{I}-\mathrm{Gc}: \mathrm{G}-$ actin $(\Delta)$, the results presented are ${ }^{125} \mathrm{I}$ counts immunoprecipitable with anti-Gc. For ${ }^{125} \mathrm{I}$-actin $(\Delta)$, the counts given were those appearing in the protein-containing fractions after Sephadex G-100 gel filtration (see text). Radioactivity is expressed in all three cases as a percentage of the cpm obtained in serum within 2 min i.v. administration. The mean results from three experiments are shown, together with the standard deviations obtained.
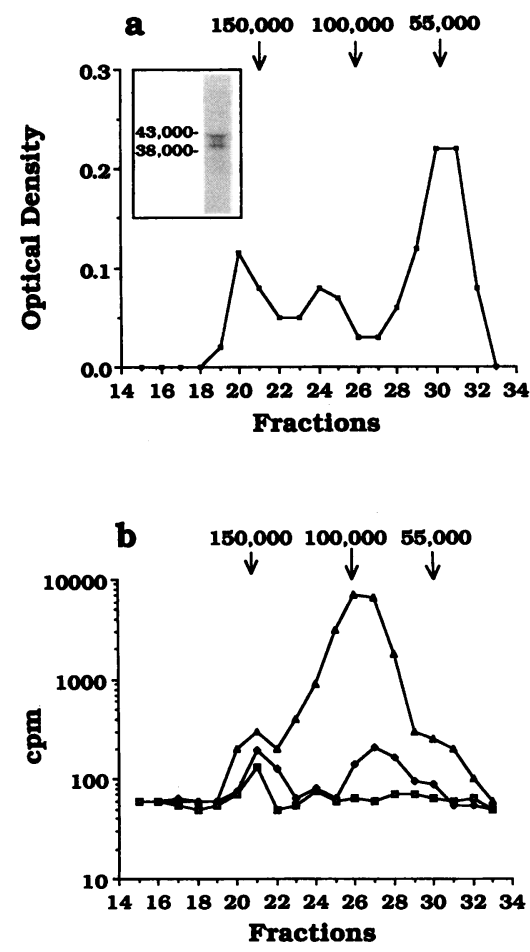

Figure 3. Gel filtration of plasma at different time points after injection of ${ }^{125} \mathrm{I}-\mathrm{G}$-actin. A. optical density trace $(280 \mathrm{~nm})$ with molecular weight markers. In the case of ${ }^{125} \mathrm{I}$-actin, counts were detected at elution volumes corresponding to $M_{\mathrm{r}} \geq 150,000$ and particularly 100,000 . The latter was also the major location of counts detected following gel filtration of purified ${ }^{125} \mathrm{I}-\mathrm{Gc}: \mathrm{G}$-actin samples, whereas native ${ }^{125} \mathrm{I}-\mathrm{Gc}$ was entirely localized in a third peak, apparent $M_{\mathrm{r}}$ 55,000 . The insert shows SDS-PAGE with autoradiography of the $M_{\mathrm{r}}$ 100,000 peak fractions obtained after immunoprecipitation with anti-Gc of a $5 \mathrm{~h}$ sample after injection of ${ }^{125} \mathrm{I}-\mathrm{G}$-actin. $(B)$ Overlay plots of cpm profiles obtained $5 \mathrm{~min}(\Delta), 9 \mathrm{~h}(\bullet)$ and $24 \mathrm{~h}(\square)$ after injection of ${ }^{125} \mathrm{I}-\mathrm{G}$-actin, indicating rapid clearance of counts related to Gc:G-actin complexes in the $M_{\mathrm{r}} 100,000$ peak. The results depicted are from a single animal, and are representative of three separate experiments.

showed that $>75 \%$ of counts were obtained in the pellet, whereas $<5 \%$ of counts were brought down in the absence of anti-Gc. Such immunoprecipitated material was examined by SDS-PAGE with autoradiography (Fig. 3). This demonstrated a radiolabeled band of $M_{\mathrm{r}} 43,000$, and an additional band, $M_{\mathrm{r}}$ 38,000 not present in the apparently homogeneous preparation initially injected (Fig. 1), which may represent a proteolytic fragment of actin, as has been described previously in vitro (37).

These results extended previous findings obtained in normal humans with G-actin in vitro (35), in indicating that the introduction of actin culminates in complexing with $\mathrm{Gc}$, even when actin is filamentous and undergoes initial depolymerization by interaction with plasma gelsolin. To investigate this point further, experiments were performed with addition of ${ }^{125}$ I-F-actin to human serum in vitro. Analysis of proteins binding actin was made by CIEP with antisera to whole human serum and Gc, and subsequent autoradiography (Fig. 4). This showed that within 5 min most of the actin added $(>80 \%)$ had complexed to a protein with $\alpha_{2}$ mobility, which was immunoreactive with anti-Gc and showed the anodal shift upon com- 

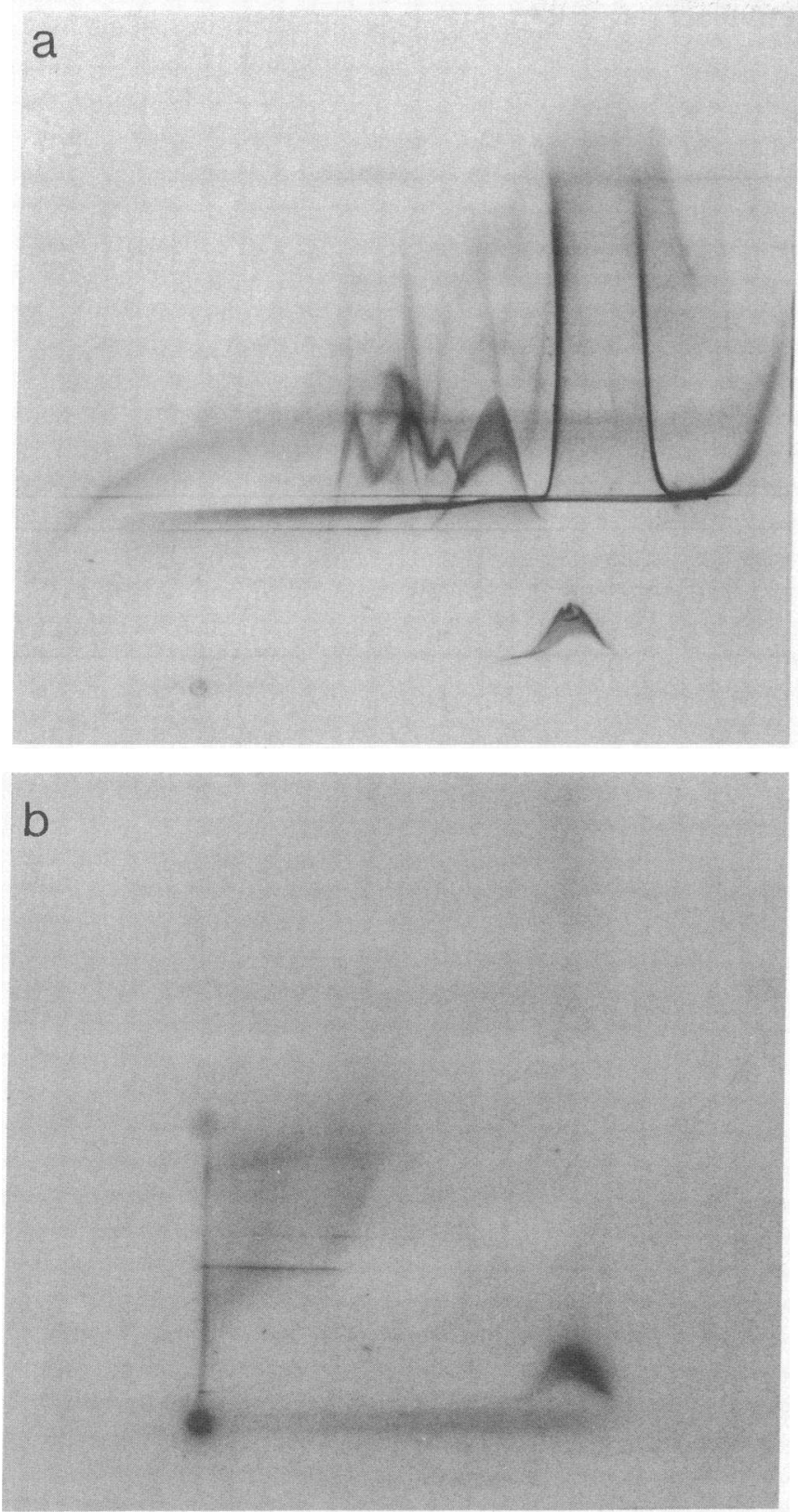

Figure 4. Binding of ${ }^{125} \mathrm{I}$-actin to $\mathrm{Gc}$ in vitro. Pelleted F-actin $(10 \mu \mathrm{g})$ together with tracer ${ }^{125} \mathrm{I}-\mathrm{F}$-actin was added to normal human serum $(10 \mu \mathrm{l})$, and after incubation for $1 \mathrm{~h}$, proteins were separated by tandem crossed immunoelectrophoresis. Samples were run horizontally (anode at right), and then vertically in the second dimension (anode at top) into gel containing antiserum to $\mathrm{Gc}$ in the bottom part (1\%) and antiserum to whole human serum in the upper part. (2\%) The gel was washed, dried and stained with Coomassie Blue. Actin-binding proteins were then analyzed by autoradiography. (a) Coomassie Blue staining.; $(b)$ autoradiography. Some counts remained at the origin, in line with use of an amount of actin which is saturating for $\mathrm{Gc}$ in this sample. However, the majority of ${ }^{125} \mathrm{I}$-actin $\rightarrow>80 \%-$ appeared to be complexed with Gc.

plexing typical of this protein. Some radioactivity was also found in the form of a smudge at the origin (Fig. 4).

Enhanced clearance of ${ }^{125} I-G$-actin after complexing with $G c$ in vivo. To examine the clearance of ${ }^{125} \mathrm{I}$-actin after complexing with $\mathrm{Gc}$ in vivo, sequential samples were subjected to
G-100 chromatography. This showed a major and progressive alteration in the proportionation of ${ }^{125} I$ counts between peaks at $M_{\mathrm{r}} \geq 150,000$ and 100,000 (cf. Fig. 3). Thus, in contrast to the preponderance of counts in the $M_{\mathrm{r}} 100,000$ peak at $5 \mathrm{~min}$, protein-bound ${ }^{125}$ I counts were equally distributed between the two peaks by $9 \mathrm{~h}$, and detectable only in the macromolecular peak at $24 \mathrm{~h}$. Although these results could have reflected instability of the Gc:G-actin interaction with progressive disruption of the complex, radioactivity was background in all other fractions. In addition, gel filtration of 5-min samples containing Gc: ${ }^{125} \mathrm{I}-\mathrm{G}$-actin (1:1 molar ratio) after incubation at $37^{\circ} \mathrm{C}$ in vitro for similar time periods up to $9 \mathrm{~h}$ showed no detectable evidence of dissociation. Overall, $>90 \%$ of counts in the $100,000-M_{\mathrm{r}}$ peak had disappeared within $5 \mathrm{~h}$. These findings were consequently consistent with formation of stable complexes between ${ }^{125} \mathrm{I}$-actin and $\mathrm{Gc}$, and their rapid and progressive removal.

Enhanced clearance of ${ }^{125} I-G c$ complexed with G-Actin. The plasma disappearance curves for ${ }^{125} \mathrm{I}-\mathrm{Gc}$ and ${ }^{125} \mathrm{I}-\mathrm{Gc}: \mathrm{G}-$ actin at steady state did not reveal any very obvious differences (Fig. 2). However, the initial phase of decay did appear to be slightly but consistently faster for ${ }^{125} \mathrm{I}-\mathrm{Gc}$ complexed with Gactin than for native ${ }^{125} \mathrm{I}-\mathrm{Gc}$, both as judged by total ${ }^{125} \mathrm{I}$ and counts obtained after immunoprecipitation with anti-Gc. The possibility of enhanced clearance of ${ }^{125} \mathrm{I}-\mathrm{Gc}$ once complexed was further examined by gel filtration of serial samples obtained after injection of ${ }^{125} \mathrm{I}-\mathrm{Gc}$ and ${ }^{125} \mathrm{I}-\mathrm{Gc}$ :G-actin (Fig. 5). At 5 min after injection of ${ }^{125} \mathrm{I}-\mathrm{Gc},>90 \%$ of protein-bound counts were found in a well-defined peak-apparent $M_{\mathrm{r}}$ 55,000 . Conversely, $5 \mathrm{~min}$ after intravenous administration of ${ }^{125} \mathrm{I}$-Gc:G-actin, only $\leq 25 \%$ of protein-bound counts were found in this peak, and $>75 \%$ were found as expected at an elution volume identical to that observed after injection of ${ }^{125} \mathrm{I}$-actin $\left(M_{\mathrm{r}} 100,000\right)$ corresponding to Gc:G-actin complexes (cf. Fig. 3). Study of later ${ }^{125}$ I-Gc:G-actin samples (Fig. 5) demonstrated that counts related to the macromolecular Gc fractions declined considerably faster ( $>90 \%$ within $5 \mathrm{~h}$ ) than those in comparable fractions containing native $\mathrm{Gc}(P$ $=0.014)$, or in animals receiving native ${ }^{125} \mathrm{I}-\mathrm{Gc}(P=0.01)$. Moreover, the decrease in the native Gc peak appeared slightly slower in rabbits injected with ${ }^{125} \mathrm{I}-\mathrm{Gc}: \mathrm{G}-$ actin than in animals

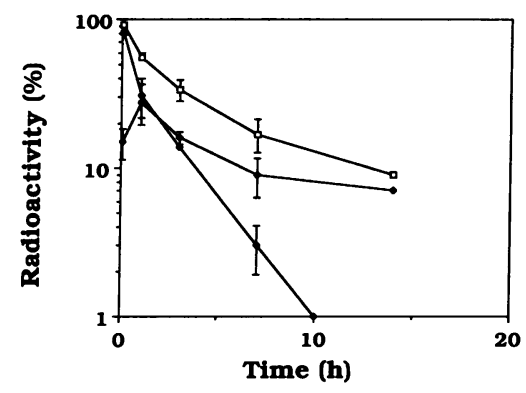

Figure 5. Enhanced clearance of Gc:G-actin complexes. Proteinbound plasma ${ }^{125}$ I counts were analyzed by Sephadex G-100 gel filtration following injection of rabbit ${ }^{125} \mathrm{I}-\mathrm{Gc}(60 \mu \mathrm{g})$ and ${ }^{125} \mathrm{I}-\mathrm{Gc}: \mathrm{G}-$ actin $(60 \mu \mathrm{g}: 160 \mu \mathrm{g})$. These curves depict the decay of counts in the $M_{\mathrm{r}} 55,000$ peak after injection of ${ }^{125} \mathrm{I}-\mathrm{Gc}(\square)$, and in the $M_{\mathrm{r}} 55,000$ $(\diamond)$ and $M_{\mathrm{r}} 100,000$ fractions $(\diamond)$ after administration of ${ }^{125} \mathrm{I}-\mathrm{Gc}: \mathrm{G}-$ actin. Radioactivity is expressed as a percentage of cpm obtained within 2 min of i.v. administration. The mean results from two experiments are shown, together with the standard deviations obtained. 
administered ${ }^{125} \mathrm{I}-\mathrm{Gc}$ alone (Fig. 5). These observations therefore suggested the possibility of processing of ${ }^{125} \mathrm{I}-\mathrm{Gc}: \mathrm{G}$-actin complexes in vivo, resulting in some shifting of ${ }^{125} \mathrm{I}-\mathrm{Gc}$ from the $M_{\mathrm{r}} 100,000$ peak to a pool eluting at $M_{\mathrm{r}} 55,000$. In addition, when ${ }^{125} \mathrm{I}-\mathrm{Gc}: \mathrm{G}$-actin was incubated with native plasma at $37^{\circ} \mathrm{C}$ in vitro for up to $7 \mathrm{hrs}$ and then subjected to chromatography, counts related to the $100,000 M_{\mathrm{r}}$ peak decreased by $<5 \%$, indicating that the reduction observed in vivo was not explicable simply on the basis of spontaneous dissociation of complexes between ${ }^{125} \mathrm{I}-\mathrm{Gc}$ and G-actin.

Clearance of ${ }^{125} I-G c,{ }^{125} I-G c$ :G-actin and ${ }^{125} I-G$-actin in nephrectomized rabbits. Since considerable excretion of counts was found in the urine after injection of ${ }^{125} \mathrm{I}-\mathrm{Gc}$ and ${ }^{125} \mathrm{I}$-actin, and similar renal localization of ${ }^{125} \mathrm{I}$ following administration of $\mathrm{Gc}$ has been noted in a previous study (19), labeled proteins were injected into animals that had undergone bilateral nephrectomy. Peritoneal dialysis achieved removal of $<5 \%$ of total counts injected, and the ${ }^{125}$ I counts in the dialysate were $<1 \%$ TCA-precipitable. Consistent with the absence of glomerular filtration, the number of free ${ }^{125} \mathrm{I}$ counts in the circulation increased progressively throughout the experiment. However, when samples were analysed by gel filtration or immunoprecipitation, the clearance curves for ${ }^{125} \mathrm{I}-\mathrm{Gc},{ }^{125} \mathrm{I}-\mathrm{G}-$ actin, and ${ }^{125} \mathrm{I}$-albumin were not significantly different from those observed in animals with functioning kidneys (Fig. 6). In addition, the pattern of tissue uptake was not substantially altered by nephrectomy.

\section{Discussion}

Within the last decade, two proteins have been described in the circulation that interact with actin in humans and in other vertebrate species. The first was described as a heat-sensitive protein able to decrease the staining of actin by anti-actin antibodies in cells (42), and to sever or destabilize filaments of actin in ultrastructural or viscosimetry studies $(23-26,43)$. This protein was further isolated and characterized $(93,000$ mol wt) $(25,44)$ and termed plasma gelsolin in respect to its structural and functional similarity with cellular gelsolin, or brevin based on its action of shortening actin filaments $(25,26$,

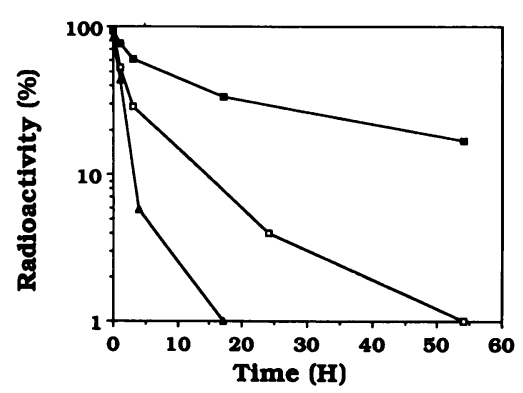

Figure 6. Plasma decay of protein-bound ${ }^{125} \mathrm{I}$ counts in nephrectomized animals after injection of $50 \mu \mathrm{g}$ rabbit ${ }^{125} \mathrm{I}-\mathrm{Gc}(\square), 60 \mu \mathrm{g}{ }^{125} \mathrm{I}-$ G-actin $(\Delta)$, and $75 \mu \mathrm{g}{ }^{125} \mathrm{I}$-albumin (ם). The results presented for ${ }^{125} \mathrm{I}$ $\mathrm{Gc}$ are after immunoprecipitation with anti-Gc, whereas ${ }^{125}$ I-G-actin results are given following Sephadex G-100 gel filtration (Fig. 2). The ${ }^{125}$ I-albumin data is in the form of total counts. Radioactivity is expressed in all three cases as a percentage of the cpm obtained in serum immediately following intravenous administration, and results shown are from single animals injected with each labeled protein.
44-48). Plasma gelsolin displays both calcium-dependent and calcium-independent effects, and interacts with actin in a polymorphous fashion (49), with each molecule possessing two distinct actin-binding sites (48, 50-53). At low plasma gelsolin:actin molar ratios, the actions of nucleating actin filament assembly, blocking the fast growing end of the filaments, and severing actin filaments, are all strongly affected by the presence of calcium $(46,50,52-54)$.

The second plasma protein found to interact with actin was identified as Gc or vitamin D-binding protein $(20,21,55)$. Gc differs from plasma gelsolin in being less heat-labile; in addition, the interaction with actin is not calcium-dependent and occurs with a stoichiometry of $1: 1$. In addition, Gc appears to undergo high affinity interaction only with $\mathrm{G}$-actin monomer $\left(K_{\mathrm{a}}=10^{8} \mathrm{M}^{-1}\right)(22)$. Direct comparison of the interactions of $\mathrm{Gc}$ and plasma gelsolin with actin have revealed that the latter affects the rate constant of actin depolymerization, whereas Gc does not (50). These observations provide a powerful stimulus for further studies of the molecular mechanisms involved in the clearance of circulating actin, and more specifically concerning the possible role of $\mathrm{Gc}$ in its removal. The most immediate question concerns the protein(s) to which actin is bound following entry into the extracellular space. Although the possibility exists that some radiolabeled protein injected might have been damaged during preparation, the proportion appeared small based on physicochemical properties and ligand binding studies (Fig. 1). In addition, although G-actin prepared by polymerization:depolymerization might have contained some oligomers, the results obtained with such recycled $\mathrm{G}$-actin were equivalent to those found with nonrecycled actin.

With these provisos, the present investigation demonstrated, as indicated earlier in vitro (35), that under the experimental conditions employed the majority of ${ }^{125}$ I-actin injected into the circulation was rapidly complexed with $\mathrm{Gc}$, regardless of whether protein was administered in soluble G- or filamentous F-form. Since depolymerization of F-actin is much slower with Gc than with plasma gelsolin, even at stoichiometric concentrations (50), the very rapid binding of ${ }^{125} \mathrm{I}$-actin monomers to Gc observed in this study following injection of ${ }^{125} \mathrm{I}-\mathrm{F}$ actin is likely to reflect initial depolymerisation of filamentous actin by plasma gelsolin $(50,56)$. This would presumably require sequential interaction of actin with gelsolin and Gc, and although this possibility has not been extensively examined, some evidence consistent with this concept does exist. Thus, in vitro experiments with purified Gc, plasma gelsolin and actin have demonstrated that Gc:G-actin complexes do not appear to bind plasma gelsolin, but that Gc can remove at least one of the two monomers of actin bound to plasma gelsolin (56). In the current experiments involving ${ }^{125} \mathrm{I}-\mathrm{F}$-actin, the majority of counts appeared to complex rapidly with $\mathrm{Gc}$ as illustrated in vivo by gel filtration and immunoprecipitation and in vitro by CIEP; a small proportion was also found in relation to other protein (Figs. 3, 4), which although not specifically tested, could possibly be plasma gelsolin (34).

Certain other evidence also indicates different but complementary functions for these two circulating actin-binding proteins. Thus, Gc can bind monomers of actin even in the presence of an excess of plasma gelsolin (56). Moreover, although much cellular actin released in the monomeric G-form is likely to be complexed with the major intracellular G-actin-sequestering protein, profilin (29), Gc displays higher apparent affin- 
ity for G-actin under defined conditions than does profilin, and can displace profilin from actin (39). Furthermore, Gc apparently binds certain fragments of actin in vitro and in vivo (37, 39 and Fig. 3, inset). Interaction of $\mathrm{Gc}$ with $\mathrm{G}$-actin is also not apparently compromised by the presence of other known ligands, such as vitamin D metabolites bound to $\mathrm{Gc}$, and/or DNase complexed with actin (20-22). Circulating Gc, which is present at relatively high concentrations $\left(300-500 \mu \mathrm{g} \mathrm{ml}^{-1}\right)$ is thus an ideal actin-sequestering protein in this compartment. Consequently, although plasma gelsolin is crucial for depolymerization of any F-actin present in the circulation, Gc may represent the final repository for the majority of actin once in monomeric form, and may thereby preserve the capacity of gelsolin to sever F-actin $(34,56)$. It also appears possible that the amount of actin complexing with gelsolin in vivo may depend upon the level of saturation of Gc, which will in turn be strongly influenced by the circulating level of this protein and the quantity of actin entering this compartment.

Since monomer actin seems to exist in the circulation mainly in the form of stable complexes with $\mathrm{Gc}$, clearance of actin from the circulation would be expected to revolve around removal of Gc:G-actin complexes. Furthermore, disappearance of the latter would be expected to be more rapid than that of the native Gc molecule. Previous studies of the effects of complexing with $25(\mathrm{OH})-\mathrm{D}_{3}$ metabolites indicated that the $t_{1 / 2}$ of $\mathrm{Gc}$ in this rabbit model $(\sim 1.7 \mathrm{~d})$ was not perceptibly influenced (19). On the other hand, more recent studies of the effects of actin complexing showed a considerable acceleration of $\mathrm{Gc}$ clearance (34). This investigation highlighted certain important potential pitfalls in studies of radioiodinated proteins with short half-lives. In particular, inaccuracies were evident when clearance measurements were made without appropriate allowance for the rapid deiodination of ${ }^{125} \mathrm{I}-\mathrm{Gc}$ and the resulting increase in free ${ }^{125} \mathrm{I}$, and also the possible secondary iodination of other unrelated proteins $(40,41)$. Although these phenomena may have occurred as a result of deiodinase activity in the circulation, they were much less marked in the case of ${ }^{125} \mathrm{I}$-albumin which had a slower turnover, and might therefore represent cellular uptake of the relevant protein. However, regardless of the mechanisms involved, the use of gel filtration and immunoprecipitation with anti-Gc did appear to permit more accurate analysis of plasma decay of ${ }^{125} \mathrm{I}$ specifically bound to $\mathrm{Gc}$ and actin.

The results showed evidence that clearance of Gc:G-actin complexes from the circulation was substantially faster than that of native $\mathrm{Gc}$ in rabbits (>90\% within $5 \mathrm{~h}$ ), as noted recently by Lind et al. (34). Moreover, extremely rapid disappearance of such complexes was observed, regardless of whether counts were introduced on Gc or actin. Since the molecular sizes of native and complexed Gc are not substantially different, the much more rapid clearance of Gc, particularly after complex formation, than of albumin, argues in favor of removal by tissue uptake, rather than mere redistribution of protein into other compartments. The rapid deiodination seen for ${ }^{125} \mathrm{I}-\mathrm{Gc}$ and ${ }^{125} \mathrm{I}-\mathrm{G}$-actin is also consistent with cellular uptake. Moreover, the decay curve obtained when ${ }^{125} \mathrm{I}-\mathrm{Gc}$ was administered together with G-actin was bimodal (Fig. 5), with rapid clearance of ${ }^{125} \mathrm{I}-\mathrm{Gc}: \mathrm{G}-$ actin, and apparently much slower disappearance of ${ }^{125} \mathrm{I}-\mathrm{Gc}$ included in the $55,000 \mathrm{M}_{\mathrm{r}}$ peak corresponding to native Gc.

The mechanism(s) responsible for uptake of Gc complexes by tissues in vivo and their subsequent fate remain to be eluci- dated. A recent plasma disappearance study in rats did not find clear evidence of enhanced clearance of complexes, although it is of interest that the half life of native $\mathrm{Gc}$ was considerably more rapid than in rabbits (57). On the other hand, the rapid appearance of large numbers of counts in various tissues studied after injection of ${ }^{125} \mathrm{I}-\mathrm{Gc}$ and ${ }^{125} \mathrm{I}-\mathrm{Gc}$ :G-actin in rabbits (19, 34) indicates that complexes are taken up substantially more rapidly, and that uptake is not limited to any single organ. It is possible that elements of the reticuloendothelial system may be involved, as is the case for another complex formed between plasma and released intracellular proteins, namely haptoglobin-hemoglobin (58). This process may also involve a specific receptor site, since we and others have described the presence of a protein indistinguishable physicochemically and immunologically from Gc on the surface membrane of peripheral blood mononuclear cells $(5,6,59,60)$, and it has been reported that mononuclear cells may bind $\mathrm{Gc}$ in vitro (61). Membrane $\mathrm{Gc}$ has also been reported on trophoblast cells (62).

These considerations suggest a conceptual model whereby actin, as a major cell protein $(29,63)$, is released into the extracellular space and rapidly removed under physiological circumstances. Actin filaments, which account for c. $50 \%$ of actin in nonmuscle cells and $>95 \%$ in muscle $(29,63)$ are rapidly fragmented by the severing action of plasma gelsolin, which increases their effective number and the number of monomeric actin molecules in equilibrium with such filaments $(29,63)$. Gc then efficiently sequesters this expanded pool of monomeric actin through formation of stable high affinity $1: 1$ complexes, and might thereby prevent glomerular filtration of G-actin (58). Most G-actin released is likely to be complexed with profilin, the major intracellular actin-sequestering protein $(29,63)$. However, profilin is probably displaced by Gc (39), resulting again in complexing of actin with Gc. Such complexes are then removed from the circulation by cellular uptake.

Based on this model, and on current knowledge concerning the concentration of $\mathrm{Gc}$ in the extracellular space (18), the clearance of complexes, and average tissue content of actin $(29,63)$, it is possible to calculate that at least $7 \mathrm{~g}$ actin could be cleared daily in normal humans. This amount of actin corresponds to the complete necrosis of $\sim 500 \mathrm{~g}$ of tissue. However, this estimate clearly requires that the concentration of $\mathrm{Gc}$ in this putative extracellular sump remain relatively constant, and that cellular uptake is matched by hepatic synthesis and possible recycling of Gc. It is also important to consider the possibility of defects in this pathway and their pathophysiological consequence(s). Although alterations in levels of plasma gelsolin might have limited effects due to the ability of this protein to depolymerize F-actin at sub-stoichiometric levels, quantitatively comparable reductions in Gc levels probably have a considerably greater effect. Very low levels of Gc have in fact been reported in individuals with severe acute liver disease, due presumably to impaired hepatic function and possibly increased consumption (31-33). Moreover, the increased percentage of circulating Gc complexes during massive hepatic necrosis (31-33) would further decrease actin-sequestering capacity. Indeed it seems likely that under these circumstances, the normal clearance mechanism for released actin may be effectively saturated, thus increasing the amount of actin bound to gelsolin and even allowing the possibility of free circulating actin. Although experiments directly testing the latter are scanty, any filamentous actin present might have 
several noxious effects (34). Plasma viscosity may be altered, and clotting may also be affected, since actin filaments interact with fibrin in vitro $(64,65)$, and actin filaments in the microcirculation may also result in sequestration of platelets. Finally, no individual completely devoid of serum $\mathrm{Gc}$ has yet been reported despite the testing of $>75,000$ samples (14), suggesting that such a deficiency would be fatal. Thus, these considerations collectively reinforce the concept that Gc plays an important role in clearance of cellular actin from the extracellular space.

\section{Acknowledgments}

Supported in part by National Institutes of Health grant DIC-33082, and by Labcatal Laboratories, Paris, France. Dr. Goldschmidt-Clermont was supported by a Medical University of South Carolina Clinical Postdoctoral Fellowship, and Dr. Galbraith was the recipient of NIH RCDA CA-00611.

\section{References}

1. Smithies, O. 1955. Zone electrophoresis in starch gels: Groupspecific variations in the serum proteins of normal human adults. Biochem. J. 61:629-641.

2. Hirschfeld, J. 1959. Immuno-electrophoretic demonstration of qualitative differences in human sera and their relation to the haptoglobins. Acta Pathol. Microbiol. 47:160-168.

3. Bearn, A. G., and H. Cleve. 1966. Genetic variations of plasma proteins. In The Metabolic Basis in Inherited Disease. J. B. Stanbury, J. B. Wyngaarden, and D. S. Frederickson, editors. McGraw-Hill, New York. 1321-1342.

4. Daiger, S. P., M. S. Schanfield, and L. L. Cavalli-Sforza. 1975. Group specific component $(\mathrm{Gc})$ proteins binds vitamin $\mathrm{D}$ and 25-hydroxy-vitamin D. Proc. Natl. Acad. Sci. USA 72:2076-2080.

5. Petrini, M., D. L. Emerson, and R. M. Galbraith. 1983. Linkage between surface immunoglobulin and the cytoskeleton of B lymphocytes may involve Gc protein. Nature 306:73-74.

6. Petrini M., R. M. Galbraith, D. L. Emerson, A. E. Nel, and P. Arnaud. 1985. Structural studies of T lymphocyte Fc receptors: Association of Gc protein with IgG bound to Fc gamma. J. Biol. Chem. 260:1804-1810.

7. Cooke, N. E., J. Walgate, and J. G. Haddad. 1979a. Human serum binding protein for vitamin D and its metabolites. I. Physiochemical and immunological identification in human tissues. J. Biol. Chem. 254:5958-5964.

8. Cooke, N. E., J. Walgate, and J. G. Haddad. 1979b. Human serum binding protein for vitamin D and its metabolites. II: Specific high affinity association with a protein in nucleated tissue. J. Biol. Chem. 254:5965-5971.

9. Schoentgen, F., M.-H. Metz-Boutique, J. Jollès, J. Constans, and P. Jollès. 1985. Homology between the human vitamin D-binding protein (group specific component), alpha fetoprotein and serum albumin. FEBS (Fed. Eur. Biol. Soc.) Lett. 185:47-50.

10. Cooke, N. E., and D. E. Vivek. 1985. Serum vitamin D-binding protein is a third member of the albumin and alpha fetoprotein gene family. J. Clin. Invest. 76:2420-2424.

11. Yang, F., J. L. Brune, S. L. Naylor, R. L. Cupples, K. H. Naberhaus, and B. H. Bowman. 1985. Human group specific component (Gc) is a member of the albumin family. Proc. Natl. Acad. Sci. USA. 82:7994-7998.

12. Cooke, N. E. 1986. Rat Vitamin D binding protein: Determination of the full-length primary structure from cloned cDNA. J. Biol. Chem. 261:3441-3450.

13. Bouillon, R., P. Van Kerkhove, and P. De Moor. 1976. Characteristics of the vitamin $\mathrm{D}$ binding protein in different species. Calc. Tiss. Res. (Suppl) 21:172-176.
14. Cleve, H. 1973. The variants of the group specific component. A review of their distribution in human populations. Isr. J. Med. Sci. 9:1133-1146.

15. Haddad, J. G. 1984. Nature and functions of the plasma binding protein for vitamin D and its metabolites. In Vitamin D: Basic and Clinical Aspects. R. Kumar, editor. Martinus Nijhoff Publishing, Boston. 383-395.

16. Bouillon, R., G. Van Doren, H. Van Baelen, and P. De Moor. 1980. Lack of effect of the vitamin $D$ staus on the concentration of the vitamin D-binding protein in rat serum. Endocrinology. 107:160-163.

17. Bouillon, R., H. Van Baelen, and P. De Moor. 1977. The measurement of the Vitamin D-binding protein in human serum. $J$. Clin. Endocrinol. Metab. 45:225-231.

18. Kawakami, M., C. B. Blum, R. Ramakrishnan, R. B. Dell, and D. S. Goodman. 1981. Turnover the plasma binding protein for vitamin D and its metabolites in normal human subjects. J. Clin. Endocrinol. Metab. 53:1110-1116.

19. Haddad, J. G., D. R. Fraser, and D. E. M. Lawson. 1981. Vitamin $D$ plasma binding protein. Turnover and fate in the rabbit. $J$. Clin. Invest. 67:1550-1560.

20. Van Baelen, H., R. Bouillon, and P. De Moor. 1980. Vitamin D-binding protein (Gc globulin) binds actin. J. Biol. Chem. 255:2270-2272.

21. Haddad, J. G. 1982. Human serum binding protein for vitamin D and its metabolites (DBP): Evidence that actin is the DBP binding component in human skeletal muscle. Arch. Biochem. Biophys. 213:538-544.

22. Goldschmidt-Clermont, P. J., R. M. Galbraith, D. L. Emerson, F. Marsot, A. E. Nel, and P. Arnaud. 1985. Distinct sites on the G-actin molecule bind Gc and DNase I. Biochem. J. 228:471-477.

23. Chaponnier C., R. Borgia, E. Rungger-Brändle, R. Weil, and G. Gabbinni. 1979. An actin-destabilizing factor is present in human plasma. Experientia (Basel). 39:1039-1041.

24. Norberg, R., R. Thorstensson, G. Utter, and A. Fagraeus. 1979. F-actin depolymerizing activity of human serum. Eur. J. Biochem. 100:575-583.

25. Harris, D. A., and J. H. Schwartz. 1981. Characterization of brevin, a serum protein that shortens actin filaments. Proc. Natl. Acad. Sci. USA. 78:6798-6802.

26. Yin, H. L., and T. P. Stossel. 1979. Control of cytoplasmic actin gel-sol transformation by gelsolin, a calcium-dependent regulatory protein. Nature (Lond.). 281:583-586.

27. Kerr, J. F. R., A. H. Wyllie, and A. R. Currie. 1972. Apoptosis: A basic biological phenomenon with wide-ranging implications in tissue kinetics. Br. J. Cancer. 26:239-257.

28. Wyllie, A. H. 1981. Cell death: A new classification separating apoptosis from necrosis. In Cell Death in Biology and Pathology. I. B. Bowen and R. A. Lockshin, editors. Chapman and Hall, London. 9-34.

29. Korn, E. D. 1982. Actin polymerization and its regulation by proteins from non-muscle cells. Physiol. Rev. 62:672-737.

30. Emerson, D. L., P. Arnaud, and R. M. Galbraith. 1938. Evidence of increased Gc: actin complexes in pregnant serum: A possible result of trophoblast embolism. Am. J. Reprod. Immunol. 4:185-189.

31. Lee, W. M., D. L. Emerson, P. A. M. Werner, P. Arnaud, P. J. Goldschmidt-Clermont, and R. M. Galbraith. 1985. Decreased serum group-specific component protein levels and complexes with actin in fulminant hepatic necrosis. Hepatology. 5:271-275.

32. Goldschmidt-Clermont, P. J., R. M. Galbraith, D. L. Emerson, A. E. Nel, and W. M. Lee. 1985. Accurate quantitation of native Gc in serum and estimation of endogenous $\mathrm{Gc}$ :Gc-actin complexes by rocket immunoelectrophoresis. Clin. Chim. Acta. 148:173-183.

33. Goldschmidt-Clermont, P. J., R. M. Galbraith, D. L. Emerson, A. E. Nel, and W. M. Lee. 1985. Evidence of circulating Gc:G-actin complexes in health and disease. In Vitamin D: Chemical, Biochemical and Clinical Update. A. W. Norman, K. Schaefer, H.-G. Grigoleit, and D.-V. Herrath, editors. Walter De Gruyter \& Co., Berlin. 1103-1104. 
34. Lind, S. E., D. B. Smith, P. A. Janmey, and T. P. Stossel. 1986. Role of plasma gelsolin and the Vitamin D-binding protein in clearing actin from the circulation. J. Clin. Invest. 78:736-742.

35. Goldschmidt-Clermont, P. J., R. M. Galbraith, D. L. Emerson, A. E. Nel, P. A. M. Werner, and W. M. Lee. 1985. Effects of ligand binding upon measurement of $\mathrm{Gc}$ by rocket immunoelectrophoresis. Implications for protein determination and for studies of protein ligand interactions. Electrophoresis. 6:155-161.

36. Rosa, U. 1976. Advances in protein labelling. In Plasma Protein Turnover. R. Bianchi, G. Mariani, and A. S. McFarlane, editors. University Park Press, Baltimore, MD. 31-44.

37. Goldschmidt-Clermont, P. J., R. C. Allen, A. E. Nel, D. L. Emerson, J. R. Day, and R. M. Galbraith. 1986. Gc (Vitamin D-binding protein) binds the $33.5 \mathrm{~K}$ tryptic fragment of actin. Life Sci. 38:735-742.

38. Pantaloni, D., M. F. Carrier, M. Cove, A. R. Lal, S.-L. Brenner, and E. D. Korn. 1984. The critical concentration of actin in the presence of ATP increases with the member concentration of filaments and approaches the critical concentration of actin AOP. J. Biol. Chem. 259:6279-6283.

39. Goldschmidt-Clermont, P. J., E. L. Van Alstyne, J. R. Day, D. L. Emerson, A. E. Nel, J. Lazarchick, and R. M. Galbraith. 1986. Gc (Vitamin D binding protein) prevents the interaction between Gactin and profilin. Biochemistry. 35:6467-6472.

40. Mach, J. P., S. Carrel, M. Forni, J. Ritschard, A. Donath, and P. Alberto. 1980. Tumor localization of radiolabeled antibodies against carcinoembryonic antigen in patients with cancer; A critical evaluation. N. Engl. J. Med. 303:5-10.

41. Stern, P., P. Hagan, S. Halpern, A. Chen, G. David, T. Adams, W. Desmond, K. Brautigan, and I. Royston. 1982. The effect of the radiolabel on the kinetics of monoclonal anti-CEA in a nude mousehuman colon tumor model. In Hybridomas in Cancer Diagnostic and treatment. M. S. Mitchell and H. F. Oettgen, editors. Raven Press, New York. 245-254.

42. Fagraeus, A., and R. Norberg 1978. Anti-actin antibodies. Curr. Topics Microbiol. Immunol. 82:1-13.

43. Harris, H. E., J. R. Bamburg, and A. G. Weeds. 1980. Actin filaments disassembly in blood plasma. FEBS (Fed. Eur. Biol. Soc.) Lett. 121:175-177.

44. Thortensson R., G. Utter, and R. Norberg 1982. Further characterization of the $\mathrm{Ca}^{2+}$-dependent $\mathrm{F}$-actin-depolymerisation protein of human serum. Eur. J. Biochem. 126:11-16.

45. Yin, H. L., and T. P. Stossel. 1980. Purification and structural properties of Gelsolin, a $\mathrm{Ca}^{2+}$-activated regulatory protein of macrophages. J. Biol. Chem. 255:9490-9493.

46. Yin, H. L., K. S. Zanek, and T. P. Stossel. $1980 . \mathrm{Ca}^{2+}$ control of actin gelation. Interaction of gelsolin with actin filaments and regulation of actin gelation. J. Biol. Chem. 255:9494-9500.

47. Yin, H. L., J. H. Albrecht, and A. Fattoum. 1981. Identification of gelsolin, a $\mathrm{Ca}^{2+}$-dependent regulatory protein of actin gel-sol transformation, and its intracellular distribution in a variety of tissues. $J$. Cell Biol. 91:901-906.

48. Bryan, J., and M. C. Kurth. 1984. Actin-gelsolin interactions: Evidence for two actin-binding sites. J. Biol. Chem. 259:7480-7487.

49. Harris, H. E., and A. G. Weeds. 1983. Plasma actin depoly- merizing factor has both Calcium-dependent and Calcium-independent effects on actin. Biochemistry. 22:2728-2741.

50. Lees, A., J. G. Haddad, and S. Lin. 1984. Brevin and vitamin D-binding protein: Comparison of the effects of two serum proteins on actin assembly and disassembly. Biochemistry. 23:3038-3047.

51. Kwiatkowski D. J., P. A. Janmey, J. E. Mole, and H. L. Yin 1985. Isolation and properties of two actin-binding domains in gelsolin. J. Biol. Chem. 260:15232-15238.

52. Porte, F., and M.-L. Harricane. 1986. Interactions of plasma gelsolin with actin. Isolation and characterization of binary and ternary plasma-gelsolin-actin complexes. Eur. J. Biochem. 154:87-93.

53. Coue, M., and E. D. Korn. 1986. Interaction of plasma gelsolin with ADP-actin. J. Biol. Chem. 261:3628-3631.

54. Janmey, P. A., C. Chaponnier, S. E. Lind, K. S. Zanek, T. P. Stossel, and H. L. Yin. 1985. Interaction of gelsolin and gelsolin-actin complexes with actin. Effects of calcium on actin nucleation, filament severing and end blocking. Biochemistry. 24:3714-3723.

55. Vandekerckhove J. S., and I. V. Sandoval. 1982. Purification and characterization of a new mammalian serum protein with the ability to inhibit actin polymerization and promote depolymerization of actin filaments. Biochemistry. 21:3983-3991.

56. Janmey, P. A., T. P. Stossel, and S. E. Lind. 1986. Sequential binding of actin monomers to plasma gelsolin and its inhibition by vitamin D-binding protein. Biochem. Biophys. Res. Commun. 136:72-79.

57. Harper, K. D., J. F. McLeod, M. A. Kowalski, and J. G. Haddad. 1987. Vitamin D binding protein sequesters monomeric actin in the circulation of the rat. J. Clin. Invest. 79:1365-1370.

58. Putnam, F. W. 1975. Haptoglobin. In The Plasma Proteins: Structure, Function and Genetic Control. Vol II. F. W. Putnam, editor. Academic Press, New York. 1-50.

59. Petrini, M., R. M. Galbraith, P. A. M. Werner, D. L. Emerson, and P. Arnaud. 1984. Gc (vitamin D-binding protein) binds the cytoplasm of all human lymphocytes and is expressed on B cell membranes. Clin. Immunol. Immunopathol. 31:282-295.

60. McLeod, J. F., M. A. Kowalski, and J. G. Haddad. 1986. Characterisation of a monoclonal antibody to human serum vitamin D-binding protein ( $\mathrm{Gc}$ globulin): Recognition of an epitope hidden in membranes of circulating monocytes. Endocrinology. 119:77-83.

61. Constans, J., F. Oksman, and M. Viau. 1981. Binding of the apo and holoform of the serum vitamin D-binding protein to human lymphocytes cytoplasm and membrane by indirect immunofluorescence. Immunol. Lett. 3:159-162.

62. Emerson, D. L., P. A. Werner, M. H. Cheng, and R. M. Galbraith. 1985. Presence of Gc (vitamin D-binding protein) and interactions with actin in human placental tissue. Am. J. Reprod. Immunol. Microbiol. 7:15-21.

63. Pollard, T. D. and J. A. Cooper. 1986. Actin and actin-binding proteins: A critical evaluation of mechanisms and functions. Annu. Rev. Biochem. 55:987-1035.

64. Laki, K., and I. Muszbek. 1974. On the interaction of F-actin with fibrin. Biochim. Biophys. Acta. 371:519-525.

65. Janmey, P. A., S. E. Lind, H. L. Yin, and T. P. Stossel. 1985. Effects of semidilute actin solution on the mobility of fibrin protofibrils during clot formation. Biochim. Biophys. Acta. 841:151-158. 